\title{
Gaviscon $^{\oplus}$ vs. omeprazole in symptomatic treatment of moderate gastroesophageal reflux. a direct comparative randomised trial
}

\author{
Denis Pouchain ${ }^{1 * \dagger}$, Marc-André Bigard ${ }^{2 \dagger}$, François Liard ${ }^{3 \dagger}$, Marc Childs ${ }^{4 \dagger}$, Annick Decaudin $^{5}$ and Donna McVey ${ }^{6}$
}

\begin{abstract}
Background: Medical management of GERD mainly uses proton pump inhibitors. Alginates also have proven efficacy. The aim of this trial was to compare short-term efficacy of an alginate (Gaviscon ${ }^{\varpi}, 4 \times 10 \mathrm{~mL} /$ day) and omeprazole (20 mg/day) on GERD symptoms in general practice.
\end{abstract}

Methods: A 14-day multicentre randomised double-blind double-dummy non-inferiority trial compared Gaviscon ${ }^{\circledast}$ $(4 \times 10 \mathrm{~mL} /$ day $)$ and omeprazole $(20 \mathrm{mg} /$ day $)$ in patients with 2-6 day heartburn episodes weekly without alarm signals. The primary outcome was the mean time to onset of the first 24-h heartburn-free period after initial dosing. Secondary outcomes were the proportion of patients without heartburn by D7, pain relief by D7, and reduction in pain intensity by D7 and D14.

Results: 278 patients were recruited; 120 were included in the Gaviscon ${ }^{\oplus}$ group and 121 in the omeprazole group for the per protocol non-inferiority analysis. The mean time to onset of the first 24-h heartburn-free period after initial dosing was 2.0 ( \pm 2.2) days for Gaviscon ${ }^{\oplus}$ and 2.0 ( \pm 2.3 ) days for omeprazole $(p=0.93)$; mean intergroup difference was $0.01 \pm 1.55$ days $(95 \% \mathrm{Cl}=-0.41$ to 0.43 ): i.e., less than the lower limit of the $95 \% \mathrm{Cl}$ of -0.5 days predetermined to demonstrate non-inferiority. The mean number of heartburn-free days by D7 was significantly greater in the omeprazole group: $3.7 \pm 2.3$ days vs. $3.1 \pm 2.1(p=0.02)$. On D7, overall quality of pain relief was slightly in favour of omeprazole $(p=0.049)$. There was no significant difference in the reduction in pain intensity between groups by D7 ( $p=0.11)$ or D14 $(p=0.08)$. Tolerance and safety were good and comparable in both groups.

Conclusion: Gaviscon ${ }^{\circledast}$ was non-inferior to omeprazole in achieving a 24-h heartburn-free period in moderate episodic heartburn, and is a relevant effective alternative treatment in moderate GERD in primary care.

Trial registration: ISRCTN62203233.

Keywords: Alginate, Gastroesophageal reflux disease (GERD), General practice, Omeprazole, Randomised controlled trial

\section{Background}

In Western countries, $20 \%$ to $40 \%$ of adults suffer from episodes of heartburn due to gastroesophageal reflux disease (GERD) [1]. In France, a questionnaire study of 8,000 adults representative of the general population found a $31.3 \%$ prevalence of GERD symptoms. GERD

\footnotetext{
* Correspondence: denis.pouchain@univ-tours.fr

† Contributed equally

${ }^{1}$ Département de Médecine Générale, Université François Rabelais, Faculté de Médecine, 10, boulevard Tonnellé, BP 3223,6, rue du Docteur Lebel

94300, Vincennes 37032, Tours Cedex 1, France

Full list of author information is available at the end of the article
}

was moderate (symptoms at least once a week) in $7.8 \%$ of cases (6\% in under-50 year-olds, $10 \%$ in over-50s) [2]. Most (86\%) moderate GERD sufferers had consulted for their symptoms, but $26 \%$ had delayed for more than one year, usually because they were not worried and/or were self-medicating. Treatment was monotherapy in twothirds of cases: proton pump inhibitors (PPI) in $45 \%$ of cases, and antacids or alginates in $46 \%$. Treatment was judged satisfactory by two-thirds of patients [2].

The efficacy of PPIs in symptomatic treatment of heartburn without esophagitis is well established $[3,4]$. The level of evidence is weaker for alginates (raft-

\section{C) Biomed Central}


forming oral suspensions/formulations), as the old comparative trials were on small samples: 286 patients overall in six trials vs. placebo [5-9]. Moreover, symptomatic efficacy is hard to assess for alginates, as formulae differ from country to country, with floating gel resistance varying by a factor of three $[10,11]$.

In case of GERD symptoms without esophagitis on endoscopy or where endoscopy is not considered necessary (esophagitis prevalence in the general population not exceeding 2\%) [1], treatment aims at rapid relief of symptoms (heartburn, acid regurgitation).

There have been no studies with a modern scientific double-blind, double-dummy design directly comparing one alginate to a PPI with heartburn as the primary clinical endpoint. We therefore performed a trial called "Gaviscon ${ }^{\circledR}$ vs. Omeprazole in symptOmatic treatment of moDerate gastroesophageal reflux" (GOOD), the aim of which was to compare short-term symptomatic efficacy and safety between an alginate $\left(\right.$ Gaviscon $^{\circledR}, 4 \times 10$ $\mathrm{mL} /$ day) and a PPI (omeprazole $20 \mathrm{mg} /$ day) in moderate GERD in a general practice setting.

\section{Methods}

\section{Design}

The GOOD trial was a 14-day multicentre randomised double-blind double-dummy non-inferiority trial comparing efficacy between Gaviscon ${ }^{\circledR}$ and omeprazole 20 mg. It recruited 90 general practitioners (GPs) so as to obtain 75 active investigators. Patients recorded symptoms 4 times a day for 2 weeks and the time of taking each treatment (morning, midday, evening and bedtime); they also recorded any onset of heartburn, and if so, at what time of day (morning, midday, evening, bedtime) and any experience of relief, and if so, at what interval after first taking the treatment. The GPs performed three mandatory assessments: D0 (inclusion visit), D7, and D14.

The trial ran from August 27 to November 29, 2010, and respected the ethical principles of the Seoul revision (2008) of the Helsinki Declaration and Good Clinical Practice. The study protocol received approval by the Comité de Protection des Personnes d'île-de-France VIII ethics committee on May 3, 2010, and was registered (N - A 100 546-10) by the Agence Française de Sécurité Sanitaire des Produits de Santé (French health products approval authority). All patients were duly informed of the trial objectives and signed an informed consent form.

\section{Study population}

Included patients were male or female, aged between 18 and 60 years, with 2 to 6 days of GERD episodes per week, with heartburn, with or without regurgitation, not taking alginate/antacid or PPI treatment for at least the preceding 2 months, and able to understand the study and to complete the self-administered questionnaires. Women of child-bearing age had to have effective birth control. Exclusion criteria were: atypical digestive or extradigestive symptoms without heartburn; gastric or duodenal ulcer; history of upper digestive tract surgery or of upper digestive tract or otorhinolaryngologic neoplasm; known hypersensitivity to at least one component of Gaviscon ${ }^{\circledR}$ or of omeprazole; known hypersensitivity to benzimidazoles; and treatment with clopidogrel, atazanavir combined with ritonavir, ketoconazole, or itraconazole. Breastfeeding women and women who knew that they were pregnant as well as patients who had participated in a therapeutic trial within the month preceding inclusion in this trial were also excluded.

Included patients were randomly allocated to one of two groups: Gaviscon ${ }^{\circledR}(4 \times 10 \mathrm{~mL} /$ day $)$, or omeprazole $20 \mathrm{mg} /$ day. Randomisation by blocks of $3(2+1)$ was double-blind. Successive blocks were balanced by $2 \mathrm{~s}$.

\section{Study products}

Gaviscon ${ }^{\circledR}$ suspension in a 150 -mL bottle (Reckitt Benckiser Healthcare France) was administered orally at a daily dose of $10 \mathrm{~mL}$ ( 2 teaspoonfuls), 4 times a day (after the three main meals and at bedtime). Omeprazole (omeprazole MYLAN ${ }^{\circledR} 20$ mg, Mylan, France) in enteric coated capsule form was administered at a daily dose of $20 \mathrm{mg}$ in the morning. Maximum treatment duration was 14 days.

The active substances of the Gaviscon ${ }^{\circledR}$ oral suspension were sodium alginate and sodium bicarbonate. The placebo was composed of hydrogenated glucose syrup, xanthane gum, methyl parahydroxybenzoate (E218), propyl parahydroxybenzoate (E216), erythrosine (E217), fennel flavour, titanium oxide, and purified water. The placebo was developed so as to have the same aspect, colour, odour and flavour as the aniseed Gaviscon ${ }^{\circledR}$ suspension.

All Gaviscon ${ }^{\circledR}$ group patients also received a capsule of omeprazole-placebo every morning for 14 days, and all omeprazole $20 \mathrm{mg}$ group patients also received 10 $\mathrm{mL}$ of Gaviscon ${ }^{\mathbb{B}}$-placebo 4 times a day (after the three main meals and at bedtime) for 14 days.

Study drugs were packaged per patient and per site according to the randomisation list.

\section{Endpoints}

The primary outcome was the mean time to onset of the first 24-h heartburn-free period after initial dosing. This outcome was assessed by the GP, based on the self-administered questionnaire filled in 4 times a day by the patient. Mean time to onset was calculated as the difference between 2 time-points: the time of taking the treatment for the first time and the date and time 
(morning, midday, evening, before bedtime) at which a 24-h heartburn-free period had been achieved.

Secondary outcomes were: (a) the mean number of days without heartburn by D7 as assessed from the patient's self-administered questionnaire; (b) patient's overall qualitative self-assessment of pain relief on D7 on a 5-point Likert scale; and (c) pain intensity on D7 and D14, assessed by the patient on a $100-\mathrm{mm}$ visual analog scale (VAS).

\section{Adverse events}

Adverse events (AEs) were collected at the two study visits (D7 and D14). An AE was defined as an untoward medical event that occurred during the study period, whether or not related to the study procedure or study products.

Severe AE (SAE) was defined as an untoward medical event that resulted in death, was life-threatening, required inpatient admission or prolongation of hospitalization, or resulted in severe or persistent disability or incapacity.

\section{Statistical analysis}

Descriptive statistical analyses were performed on the data collected on D0, D7 and D14, and those of the self-administered questionnaire (D0 to D7, and D7 to D14), for the intention-to-treat (ITT) and per protocol (PP) populations. The PP population included all patients from the ITT population who attended at least one of the study visits, except those with major protocol deviations liable to interfere with the primary outcome result. As the objective of the GOOD trial was to determine whether Gaviscon ${ }^{\circledR}$ was non-inferior to omeprazole $20 \mathrm{mg}$, the PP population was the reference for efficacy analysis, and the efficacy results presented here are those for the PP population.

Inter-group statistical comparison used appropriate one-tailed tests: $\mathrm{Chi}^{2}$ test for qualitative variable (or Fisher's exact test in case of sample size $<5$ ), Student $t$ test for Gaussian quantitative variables, and non-parametric Wilcoxon test for semi-quantitative or non-Gaussian quantitative variables.

Group comparison used analysis of variance (ANOVA) when variable distribution was normal. Intergroup comparability was checked at inclusion for heartburn frequency and severity, GERD duration, age, regurgitation and alcohol consumption. In case of noncomparability, analysis of covariance (ANCOVA) was performed, introducing into the model the variable or variables that were non-comparable at baseline.

If the distribution of time to a 24-h heartburn-free period was non-normal, a non-parametric Wilcoxon test was used, with the Hodges-Lehmann median estimated with its $95 \%$ confidence interval (CI).
Statistical analysis was carried out on SAS version 8.2 (SAS Institute, North Carolina, USA). The significance threshold was set at $5 \%$.

\section{Choice of the lower limit}

In non-inferiority studies, the lower limit is classically set at $50 \%$ of the reference substance effect in comparison to placebo [12]. Previous studies showed that the time to a 24-h heartburn-free period was 19-21 days with placebo [13], 4-5 days with rabeprazole $20 \mathrm{mg}$ [13], and 2 days with pantoprazole $20 \mathrm{mg}$ or omeprazole 20 mg [14] (at least 16 days' difference between placebo and PPI). Halving this difference gives a non-inferiority limit of 8 days, which was neither ethically nor clinically acceptable.

The most recent study [14] reported a value of $1.8 \pm$ 0.8 day for omeprazole $20 \mathrm{mg}$. The GOOD trial hypothesized that omeprazole $20 \mathrm{mg}$ provides a time to onset of the first 24-h heartburn-free period of $2 \pm 1$ days. As patients recorded symptoms 4 times a day, the non-inferiority of Gaviscon ${ }^{\circledR}$ would be demonstrated by a clinically relevant value of 0.5 days less than for omeprazole $20 \mathrm{mg}$.

For the non-inferiority test, the mean time difference in onset of the first 24-h heartburn-free period between treatment groups was used, with its $95 \%$ CI. If the lower limit (0.5 days) was within this confidence interval, the non-inferiority hypothesis was taken to be confirmed.

\section{Sample size calculation}

For an $\alpha$-risk of $<5 \%$ and power of $95 \%$, the requisite sample size was 88 assessable patient data sets per group. To allow for incomplete recording of symptoms by patients and loss to follow-up $(<10 \%), 30 \%$ extra patients were to be recruited: i.e., 120 patients per group. In all, 240 patients were required in order to meet the primary endpoint. 90 investigation centres were set up, recruiting three patients each with a 3.5 month deadline.

\section{Results}

278 patients were recruited by 75 French GPs and 241 included for efficacy analysis in the PP population: 120 in the Gaviscon ${ }^{\circledR}$ group and 121 in the omeprazole 20 mg group (Figure 1).

At inclusion, PP population characteristics were comparable between groups (Table 1) and did not differ from those of the ITT population (data not shown).

The mean age of included patients (PP population) was $45.4 \pm 11.5$ years (SD). Mean body mass index (BMI) was $26.1 \pm 5.0 \mathrm{~kg} / \mathrm{m}^{2}$, and $20 \%$ of patients had BMI $\geq 30 \mathrm{~kg} / \mathrm{m}^{2}$. Patients had suffered from GERD for a mean $6.5 \pm 7.1$ years and reported a mean 4.4 days of heartburn episodes in the week preceding inclusion. 
ITT and

Safety population
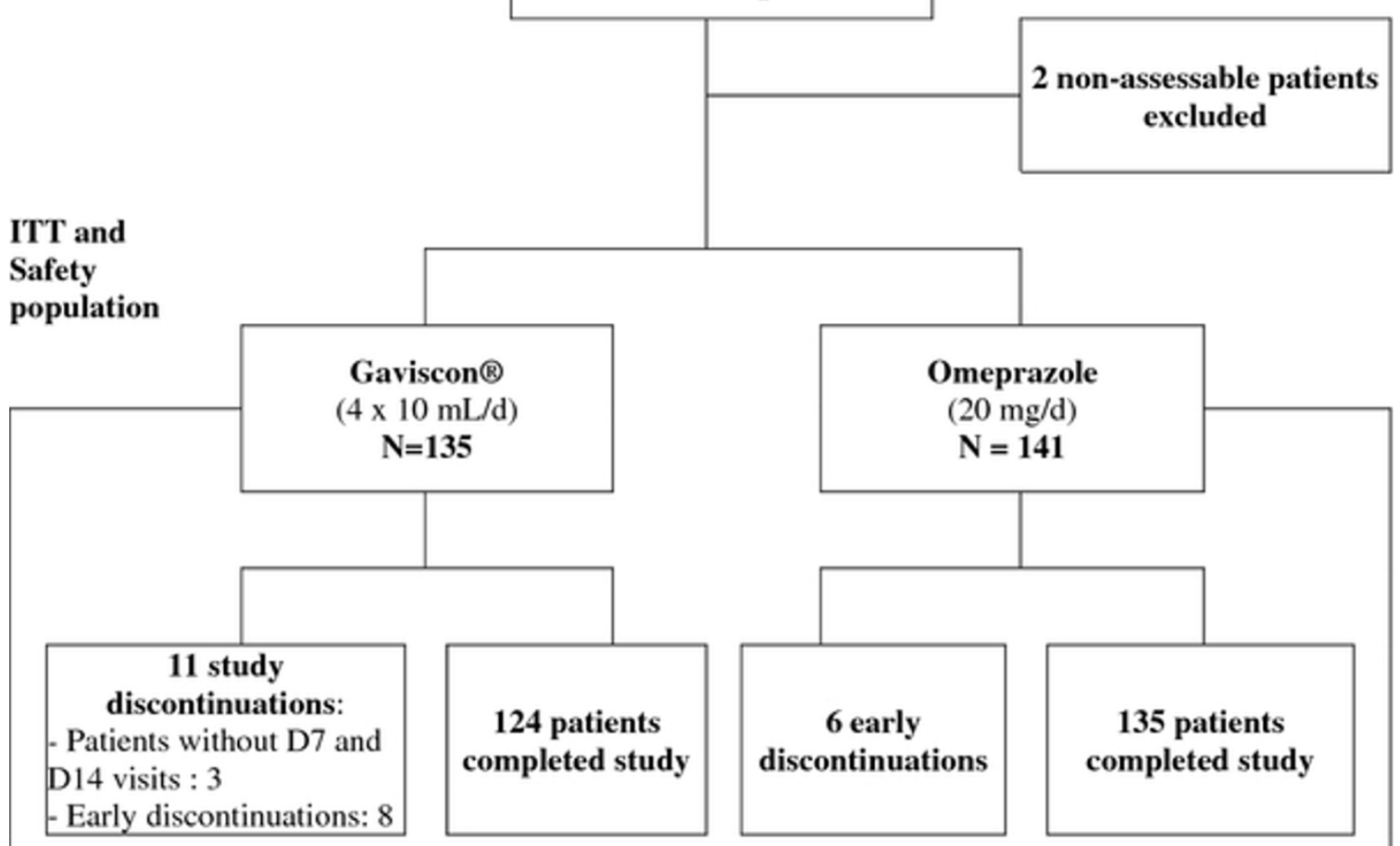

15 patients excluded from PP population

Major deviation: 14 patients

Stopped Treatment: 1 patient

PP population

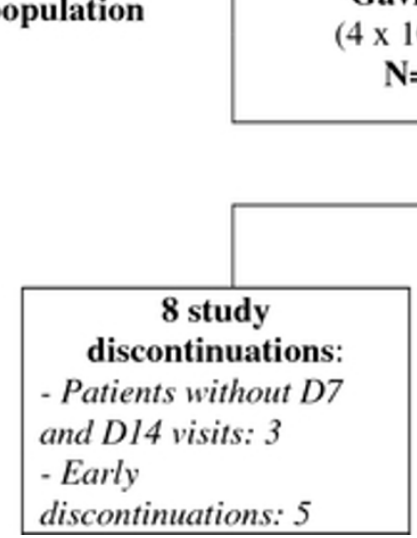

Gaviscon ${ }^{\circledR}$

$(4 \times 10 \mathrm{~mL} / \mathrm{d})$ $\mathrm{N}=120$

Figure 1 Study patients flowchart
Before inclusion, 78 patients (32.4\%) underwent endoscopy: results were normal for $34.6 \%$; $30.8 \%$ showed hiatus hernia and $28.2 \%$ mild to moderate esophagitis. No patients reported history of severe esophagitis. Alcohol consumption and smoking were moderate and comparable between groups.

The percentage of patients with very good or good compliance with medication was similar $(p=0.08)$ 
Table 1 Baseline characteristics of the patients (per protocol population)

\begin{tabular}{|c|c|c|}
\hline & $\begin{array}{c}\text { Gaviscon }^{(\mathbb{R}} \\
\mathrm{N}=120\end{array}$ & $\begin{array}{l}\text { Omeprazole } \\
\mathrm{N}=121\end{array}$ \\
\hline Age, years: mean (SD) & $46.3(10.7)$ & $44.5(12.2)$ \\
\hline Women: N (\%) & $73(60.8)$ & $65(53.7)$ \\
\hline Weight, kg: mean (SD) & $73.3(14.8)$ & $74.5(16.1)$ \\
\hline $\mathrm{BMl}, \mathrm{kg} / \mathrm{m}^{2}:$ mean (SD) & $26.0(5.2)$ & $26.2(4.7)$ \\
\hline $\mathrm{BMI} \geq 30 \mathrm{~kg} / \mathrm{m}^{2}: \mathrm{N}(\%)$ & $19(15.8)$ & $23(19.0)$ \\
\hline GERD, time to diagnosis, years: mean (SD) & $4.7(6.3)$ & $5.3(7.3)$ \\
\hline History of upper endoscopy: N (\%) & $34(28.3)$ & $44(36.4)$ \\
\hline \multicolumn{3}{|l|}{ Number of days with heartburn per week } \\
\hline$-2: N(\%)$ & $9(7.5)$ & $6(5.0)$ \\
\hline$-3: N(\%)$ & $29(24.2)$ & $24(19.8)$ \\
\hline$-4: N(\%)$ & $35(29.2)$ & $27(22.3)$ \\
\hline$-5: N(\%)$ & $17(14.2)$ & $28(23.1)$ \\
\hline$-6: N(\%)$ & $30(25.0)$ & $36(29.8)$ \\
\hline - Mean: N (SD) & $4.3(1.3)$ & $4.5(1.2)$ \\
\hline \multicolumn{3}{|l|}{ Heartburn } \\
\hline - Mild: N (\%) & $10(8.3)$ & $15(12.4)$ \\
\hline - Moderate: N (\%) & $83(69.2)$ & $73(60.3)$ \\
\hline - Severe: N (\%) & $27(22.5)$ & $33(27.3)$ \\
\hline $\begin{array}{l}\text { Heartburn-related pain (VAS), mm: mean } \\
\text { (SD) }\end{array}$ & $52(22)$ & $53(22)$ \\
\hline Systolic BP, mmHg: mean (SD) & $\begin{array}{l}124.8 \\
(10.8)\end{array}$ & $125.4(11.0)$ \\
\hline Diastolic BP, mmHg: mean (SD) & $74.4(8.5)$ & $74.2(8.2)$ \\
\hline Heart rate, beat/min: mean (SD) & $72.6(7.5)$ & $72.1(9.0)$ \\
\hline Smoking, Yes: N (\%) & $26(21.7)$ & $27(22.3)$ \\
\hline Alcohol consumption, Yes: N (\%) & $29(24.2)$ & $37(30.6)$ \\
\hline Living alone: N (\%) & $25(20.8)$ & $37(30.6)$ \\
\hline In couple: N (\%) & $95(79.2)$ & $84(69.4)$ \\
\hline \multicolumn{3}{|l|}{ Place of residence } \\
\hline - Rural & $37(30.8)$ & $37(30.6)$ \\
\hline - Suburban & $35(29.2)$ & $34(28.1)$ \\
\hline - Town & $33(27.5)$ & $25(20.7)$ \\
\hline - City & $15(12.5)$ & $25(20.7)$ \\
\hline Occupationally active & $91(75.8)$ & $80(66.1)$ \\
\hline
\end{tabular}

between the Gaviscon ${ }^{\circledR}$ (95.7\%) and omeprazole (95.9\%) groups.

\section{Efficacy \\ Primary outcome}

Mean time to onset of the first 24-h heartburn-free period after initial dosing was $2.0 \pm 2.2$ days in the Gavis$\operatorname{con}^{\circledR}$ group vs. $2.0 \pm 2.3$ days in the omeprazole group $(p=0.93)$. Mean intergroup difference was $0.01 \pm 1.55$ days (95\% CI:- 0.41 to 0.43 ): i.e., less than the lower limit of the predetermined $95 \%$ CI $(-0.5)$, thus demonstrating the non-inferiority of Gaviscon ${ }^{\circledR}$ compared to omeprazole $20 \mathrm{mg}$ (Table 2).

\section{Secondary outcomes}

The mean number of heartburn-free days by D7 was significantly greater in the omeprazole $20 \mathrm{mg}$ than in the Gaviscon ${ }^{\circledR}$ group: $3.7 \pm 2.3$ vs. $3.1 \pm 2.1$ days (absolute difference $=0.6$ days; $p=0.02$ ) (Table 3 ).

By D7, overall self-assessed qualitative pain relief was also in favour of omeprazole: $p=0.049$ (Table 4).

There was no significant difference between groups in clinically relevant reduction in pain intensity: $p=0.11$ by $\mathrm{D} 7$ and $p=0.08$ by D14 (Table 5 ).

\section{Safety}

All patients took at least one dose of Gaviscon ${ }^{\circledR}$ or omeprazole $20 \mathrm{mg}$, and were thus included in the safety analysis. Results are therefore presented for the ITT population.

Seventeen (12.6\%) of the 135 patients in the Gaviscon ${ }^{\circledR}$ group vs. 20 (14.2\%) of the 141 patients in the omeprazole $20 \mathrm{mg}$ group experienced at least one $\mathrm{AE}$ during the study $(p=0.70)$. The percentage of patients with at least one $\mathrm{AE}$ was also comparable, regardless of time period: $9.1 \%$ in the Gaviscon ${ }^{\circledR}$ group vs. $9.2 \%$ in the omeprazole group between D0 and D7 $(p=0.97)$ and respectively $5.5 \%$ vs. $5.8 \%$ between D7 and D14 $(p=0.91)$.

The most frequently observed AEs were nausea (1.8\%), constipation (1.5\%), rhinopharyngitis (1.5\%), drug intolerance (1.1\%), abdominal pain, diarrhoea, abdominal distension, rhinitis and cough $(0.7 \%$ each). All other AEs had an incidence of $0.4 \%$ each.

One patient in the omeprazole $20 \mathrm{mg}$ group experienced one SAE (bowel obstruction).

\section{Discussion}

The GOOD trial is the first randomised controlled double-blind, double-dummy trial to directly compare efficacy between an alginate and a PPI with heartburn as the clinical primary endpoint. It showed that Gaviscon ${ }^{\circledR}$ $(4 \times 10 \mathrm{~mL} /$ day $)$ was not inferior to omeprazole $20 \mathrm{mg} /$ day in achieving onset of the first 24-h heartburn-free period after initial dosing in patients with moderate GERD (heartburn at least once a week). Mean times to onset of the first 24-h heartburn-free period after initial dosing were $2 \pm 2.2$ days for Gaviscon ${ }^{\circledR}$ and $2 \pm 2.3$ days for omeprazole $(p=0.93)$. In both groups, 9 out of 10 patients had a heartburn-free period of at least $24 \mathrm{~h}$.

The mean number of heartburn-free days by D7 was significantly $(p=0.02)$ greater with omeprazole, due to a higher rate of symptom recurrence in the Gaviscon ${ }^{\circledR}$ group. The weekly absolute difference was 0.6 days.

There was no significant difference between groups in clinically relevant reduction in pain intensity, although overall qualitative pain relief was slightly $(p=0.049)$ in favour of omeprazole. 
Table 2 Mean time to onset of the first 24-h heartburn-free period after initial dosing and number of patients free from heartburn for $24 \mathrm{~h}$ (per protocol population)

\begin{tabular}{lcc}
\hline & $\begin{array}{c}\text { Gaviscon }{ }^{\circledR} \\
\mathbf{N}=\mathbf{1 2 0}\end{array}$ & $\begin{array}{c}\text { Omeprazole } \\
\mathbf{N}=\mathbf{1 2 1}\end{array}$ \\
\hline Mean time to the onset of a 24-h heartburn-free period, days: mean (SD) & $2.0(2.2)$ & $2.0(2.3)$ \\
\hline Median, days & 1.2 & 1.2 \\
\hline Number of patients free of heartburn for 24 h: N (\%) & $105(89.7)$ & $109(90.1)$ \\
\hline $\begin{array}{l}\text { The proportion of patients achieving a first 24-h heartburn-free period was 105/120 (89.7\%) in the Gaviscon }{ }^{\circledR} \text { group, vs. 109/121 (90.1\%) in the omeprazole group } \\
(p=0.93) .\end{array}$
\end{tabular}

Results of the GOOD trial also showed that Gaviscon ${ }^{\circledR}$ and omeprazole $20 \mathrm{mg}$ could be used both safely.

This trial, performed in a general practice setting, included patients with symptoms highly suggestive of GERD (heartburn, regurgitation) and with a very low estimated risk of ulcerative esophagitis. The same primary outcome was used in a trial comparing rabeprazole vs. placebo in GERD patients without erosive or ulcerated esophagitis on endoscopy [13]. In the rabeprazole $20 \mathrm{mg} /$ day group, the median time to a 24-h heartburnfree period was 4.5 days, vs. 21.5 with placebo. A trial comparing pantoprazole $20 \mathrm{mg} /$ day and esomeprazole $20 \mathrm{mg} /$ day in GERD without esophagitis found a median 2 days to the beginning of heartburn relief in both groups [14].

Alginates showed proven efficacy against GERD symptoms in randomised trials vs. placebo [5-9]. As the medications in both arms of the GOOD trial had proven short-term symptomatic efficacy in GERD vs. placebo, no placebo arm was deemed necessary.

The limitation of the GOOD trial was the treatment period, which was only 14 days, with the primary outcome set during the first 7 days of treatment. The objective was to determine whether Gaviscon ${ }^{\circledR}$ could be a relevant alternative to omeprazole $20 \mathrm{mg}$ in patients suffering from mild-to-moderate episodic GERD in primary care, not requiring prolonged continuous treatment. These patients represent $74 \%$ of those consulting a primary care physician with a GERD complaint [2], and require short-term treatment only. As the primary outcome was the time to onset of the first 24-h heartburnfree period, each day was divided into four periods so as to have four symptom assessments per day. As the treatment was symptomatic, this endpoint was relevant clinically and from the patient's point of view. Patients in the GOOD trial had moderate GERD, and therefore probably belonged to the population of patients able to use over-the-counter PPIs, which in France are packaged for a 14-day course of treatment.

The comparison was between two drugs with different pharmacokinetic and pharmacodynamic properties. Omeprazole $20 \mathrm{mg}$ is somewhat pharmacologically effective as of D1, inhibiting 70\% of proton pumps, with efficacy increasing up to D3 [15]. Alginates display immediate action, forming a raft floating over the stomach contents, eliminating or displacing the postprandial "acid pocket", so that, in case of reflux, the raft is regurgitated first into the lower oesophagus, reducing acid contact, especially when the subject is standing [16-21]. The raft may remain in the stomach for several hours [18] but is then evacuated, so that 3 or 4 doses per day are required for optimal efficacy.

The trial used a simple, relevant and pragmatic primary clinical endpoint rather than a composite score such as symptom frequency plus intensity. On the secondary endpoints, the results were marginally $(P=$ 0.049 ) in favour of better efficacy for omeprazole $20 \mathrm{mg}$ on overall qualitatively perceived pain relief (but not on

Table 3 Mean number of days without heartburn by D7 (per protocol population)

\begin{tabular}{|c|c|c|c|c|}
\hline & & $\begin{array}{c}\text { Gaviscon }^{\circledR} \\
N=120 \text { (\%) }\end{array}$ & $\begin{array}{l}\text { Omeprazole } \\
\mathrm{N}=121(\%)\end{array}$ & $p$-value \\
\hline \multirow[t]{9}{*}{ Number of days without heartburn } & 0 & $19(16.5)$ & $15(12.7)$ & 0.33 \\
\hline & 1 & $10(8.7)$ & $10(8.5)$ & \\
\hline & 2 & $17(14.8)$ & $12(10.2)$ & \\
\hline & 3 & $22(19.1)$ & $16(13.6)$ & \\
\hline & 4 & $18(15.7)$ & $16(13.6)$ & \\
\hline & 5 & $10(8.7)$ & $15(12.7)$ & \\
\hline & 6 & $13(11.3)$ & $20(16.9)$ & \\
\hline & 7 & $6(5.2)$ & $14(11.9)$ & \\
\hline & Mean (SD) & $3.1(2.1)$ & $3.7(2.3)$ & 0.02 \\
\hline
\end{tabular}


Table 4 Overall quality of pain relief by D7 (per protocol population)

\begin{tabular}{|c|c|c|c|}
\hline & $\begin{array}{c}\text { Gaviscon }^{\circledR} \\
\mathrm{N}=120(\%)\end{array}$ & $\begin{array}{l}\text { Omeprazole } \\
\mathrm{N}=121(\%)\end{array}$ & $p$-value \\
\hline Much worse & $0(0)$ & $1(0.8)$ & 0.049 \\
\hline A little worse & $4(3.4)$ & $1(0.8)$ & \\
\hline No change & $10(8.5)$ & $5(4.2)$ & \\
\hline A little better & $41(35.0)$ & $38(31.9)$ & \\
\hline Much better & $62(53.0)$ & $74(62.2)$ & \\
\hline
\end{tabular}

pain intensity) and mean number of heartburn-free days between D0 and D7, were in agreement with many literature reports of omeprazole $20 \mathrm{mg}$ 's efficacy on reflux symptoms with or without esophagitis [20].

In the last 15 years, several guidelines have been published [22-28], but mainly focused on GERD requiring a medical opinion from a gastroenterologist (disabling and/or continuous symptoms, esophagitis on endoscopy, extra-digestive manifestations, and treatment failure). In these patients, alginates and antacids were often restricted to self-medication. The GOOD trial demonstrated a role for Gaviscon ${ }^{\circledR}$ in the management of moderate GERD with occasional recurrence, alongside ondemand PPIs in patients showing rapid response to the latter [29]. This is a relevant and useful alternative and an effective non-systemic approach that should help reduce excessive use of curative or preventive prescriptions of PPIs [30]. PPIs are a well-tolerated pharmacologic class, but concomitant prescription of omeprazole with clopidogrel should be managed carefully after coronary stenting [31-33]. Some authors suggested that prolonged PPI therapy could increase Clostridium difficile infection [34], community-acquired pneumopathy [35] and risk of hip fracture [36,37], so that this pharmacologic class should be prescribed in moderation if other safe rapid-relief solutions are available.

\section{Conclusion}

In a general practice setting for patients complaining of moderate heartburn, Gaviscon ${ }^{\circledR}(4 \times 10 \mathrm{~mL} /$ day $)$ is an effective short-term treatment option in mild-to-moderate GERD, in terms of onset of a first 24-h heartburn-

Table 5 Pain intensity by D0, D7 and D14: 100-mm visual analog scale (per protocol population)

\begin{tabular}{lccc}
\hline & $\begin{array}{c}\text { Gaviscon } \\
\mathbf{N}=\mathbf{1 1 6}\end{array}$ & $\begin{array}{c}\text { Omeprazole } \\
\mathbf{N}=\mathbf{1 1 8}\end{array}$ & p-value \\
\hline D0, mm, mean (SD) & $51(22)$ & $53(22)$ & 0.52 \\
\hline D7, mm, mean (SD) & $17(17)$ & $14(17)$ & 0.11 \\
\hline$\triangle$ D0-D7, mm, mean (SD) & $-34(27)$ & $-39(26)$ & 0.12 \\
\hline Day 14, mm, mean (SD) & $13(18)$ & $10(16)$ & 0.08 \\
\hline$\triangle$ D0-D14, mm, mean (SD) & $-38(27)$ & $-44(27)$ & 0.11 \\
\hline
\end{tabular}

free period after initial dosing. It proved non-inferior to omeprazole $20 \mathrm{mg} /$ day, and is thus a relevant and effective alternative treatment in case of moderate and episodic symptoms of GERD as managed in general practice.

\begin{abstract}
Acknowledgements
The study was funded by an unrestricted grant from Reckitt Benckiser Healthcare France.

Data collection and analyses were undertaken by Mediscan (MC) and received funding from Reckitt Benckiser Healthcare France. Writing support was provided by Fabienne Peretz, independent medical writer and funded by Reckitt Benckiser Healthcare France.

The authors had full and sole responsibility for the study design, data collection, statistical analysis, and interpretation of the data and for the writing of the report. The authors had complete independence as to the design, integrity and publication of the study, without any intervention from the pharmaceutical partner.
\end{abstract}

\section{Author details}

'Département de Médecine Générale, Université François Rabelais, Faculté de Médecine, 10, boulevard Tonnellé, BP 3223,6, rue du Docteur Lebel 94300, Vincennes 37032, Tours Cedex 1, France. ${ }^{2} \mathrm{CHU}$ de Nancy, Hôpital de Brabois, rue du Morvan, 54500 Vandœuvre-lès-Nancy, France. ${ }^{3}$ General Practice, 37800 Saint-Epain, France. ${ }^{4}$ Mediscan, 20, rue Saint-Saëns, 75015 Paris, France. ${ }^{5}$ Reckitt Benckiser Healthcare France, 15, rue Ampère, 91748 Massy Cedex, France. ${ }^{6}$ Reckitt Benckiser Group plc, 103-105 Bath Road, Slough, Berkshire SL1 3UH, UK.

\section{Authors' contributions}

$D P, M A B$ and $M C$ designed the study. FL participated in the design. MC conducted the data collection and designed and carried out the statistical analysis. DP wrote the article. All authors participated in critical revision of the manuscript and have seen and approved the final version. DP is the guarantor of this trial.

\section{Competing interests}

Denis Pouchain, MD: served as a consultant for Reckitt Benckiser Healthcare France and Bayer Healthcare Consumer Care and received funding from Reckitt Benckiser Healthcare France to lead this trial.

Marc-André Bigard, MD: served as speaker, consultant and advisory board member for Abbott, AstraZeneca, Bayer Healthcare, Ferring, IPRAD, Sanofi, Schering-Plough, and Reckitt Benckiser Healthcare France.

François Liard, MD: served as speaker, consultant and advisory board member for Lündbeck, Reckitt Benckiser Healthcare France, Bayer Healthcare, Menarini, Sanofi, Pfizer, and Biocodex.

Marc Childs, MD: employee of Mediscan, CRO in charge of the study funded by Reckitt Benckiser Healthcare France.

Annick Decaudin, PharmD: Reckitt Benckiser Healthcare, France.

Donna McVey, MD: Reckitt Benckiser, United Kingdom.

Received: 9 October 2011 Accepted: 23 February 2012

Published: 23 February 2012

\section{References}

1. Spechler SJ: Epidemiology and natural history of gastro-oesophageal reflux disease. Digestion 1992, 51(Suppl 1):24-29.

2. Bretagne JF, Richard-Molard B, et al: Gastroesophageal reflux in the French general population: national survey of 8000 adults. Presse Med 2006, 35:23-31.

3. van Pinxteren B, Sigterman KE, Bonis $P$, Lau J, Numans ME: Short-term treatment with proton pump inhibitors, $\mathrm{H} 2$-receptor antagonists and prokinetics for gastro-oesophageal reflux disease-like symptoms and endoscopy negative reflux disease. Cochrane Database of Systematic Reviews 2010, 11, Art. No.: CD002095. DOI: 10.1002/14651858.CD002095. pub4.

4. Dean BB, Gano AD Jr, Knight K, et al: Effectiveness of proton pump inhibitors in non-erosive reflux disease. Clin Gastroenterol Hepatol 2004, 2:656-664 
5. Stanciu C, Bennett JR: Alginate-antacid in the reduction of gastrooesophageal reflux. Lancet 1974, 1:109-111.

6. Filoche B, Carteret E, Couzigou B, et al: Randomized double-blind trial with a liquid suspension of alginate for the treatment of pyrosis. Gastroenterol Clin Biol 1991, 15:984-985.

7. Grossmann AE, Klotz AP, Rhodes JB, Korb T: Reflux oesophagitis. A comparison of old and new medical management. J Kans Med Soc 1973, 74:423-424.

8. Barnardo DE, Lancaster-Smith M, Strickland ID, Wright JT: A double-blind controlled trial of "Gaviscon" in patients with symptomatic gastrooesophageal reflux. Curr Med Res Opin 1975, 3:388-391.

9. Beeley M, Warner JO: Medical treatment of symptomatic hiatus hernia with low-density compounds. Curr Med Res Opin 1972, 1:63-69.

10. Chatfield S: A Comparison of the efficacy of the alginate preparation, Gaviscon advance, with placebo in the treatment of gastro-oesophageal reflux disease. Curr Med Res Opin 1999, 15:152-159.

11. Hampson FC, Farndale A, Strugala V, et al: Alginate rafts and their characterisation. Int J Pharm 2005, 294:137-147.

12. D'Agostino RB, Massaro JM, Sullivan LM: Non-inferiority trials: design, concepts and issues - the encounters of academic consultants in statistics. Statist Med 2003, 22:169-186.

13. Miner P Jr, Orr W, Filippone J, et al: Rabeprazole in non-erosive gastroesophageal reflux disease: a randomized placebo-controlled trial. Am J Gastroenterol 2002, 97:1332-1339.

14. Monnikes H, Pfaffenberger B, Gatz G, et al: Novel measurement of rapid treatment success with ReQuest: first and sustained symptom relief as outcome parameters in patients with endoscopy-negative GERD receiving $20 \mathrm{mg}$ pantoprazole or $20 \mathrm{mg}$ esomeprazole. Digestion 2005, 71:152-158.

15. Shin JM, Sachs G: Pharmacology of proton pump inhibitors. Curr Gastroenterol Rep 2008, 10:528-534.

16. Castell DO, Dalton CB, Becker D, et al: Alginic acid decreases postprandial upright gastroesophageal reflux. Comparison with equal-strength antacid. Dig Dis Sci 1992, 37:589-593.

17. Lambert JR, Korman MG, Nicholson L, Chan JG: In-vivo anti-reflux and raft properties of alginates. Aliment Pharmacol Ther 1990, 4:615-622.

18. Mandel KG, Daggy BP, Brodie DA, Jacoby HI: Review article: alginate-raft formulations in the treatment of heartburn and acid reflux. Aliment Pharmacol Ther 2000, 14:669-690.

19. Armstrong $\mathrm{D}$, Talley $\mathrm{NJ}$, Lauritsen $\mathrm{K}$, et al: The role of acid suppression in patients with endoscopy-negative reflux disease: the effect of treatment with esomeprazole or omeprazole. Aliment Pharmacol Ther 2004, 20:413-421.

20. Sontag SJ, Hirschowitz BI, Holt S, et al: Two doses of omeprazole versus placebo in symptomatic erosive esophagitis: the U.S. Multicenter Study. Gastroenterology 1992, 102:109-118.

21. Kwiatec MA, Roman SA, Fareeduddin A: An alginate-antacid formulation (Gaviscon Double Action Liquid) can eliminate or displace the postprandial "acid pocket" in symptomatic GERD patients. Aliment Pharmacol Ther 2011, 34:59-66.

22. An evidence-based appraisal of reflux disease management-the Genval Workshop Report. Gut 1999, 44(suppl 1):1-16.

23. Gastroesophageal reflux in adults: diagnosis and treatment. Conclusions of Consensus Conference: long text. Organized by the French National Society of Gastroenterology and Belgian Royal Society of Gastroenterology/Flemish Society of Gastroenterology. French Society of Digestive Surgery. French Society of Digestive Endoscopy. French Society of Pharmacology. Gastroenterol Clin Biol 1999, 23:56-65.

24. New Castle Guideline Development and Research Unit. Dyspepsia: Management of dyspepsia in adults in primary care. National Institute for Clinical Excellence. Clinical Guideline 17 2004, 47, Available at: http:// www.nice.org.uk/nicemedia/pdf/CG017NICEguideline.pdf. Last access: 24 August 2011.

25. Fock KM, Talley N, Hunt R, et al: Report of the Asia-Pacific consensus on the management of gastroesophageal reflux disease. J Gastroenterol Hepatol 2004, 19:357-367.

26. DeVault KR, Castell DO: Updated guidelines for the diagnosis and treatment of gastroesophageal reflux disease. Am J Gastroenterol 2005, 100:190-200
27. Armstrong D, Marshall JK, Chiba N, et al: Canadian Consensus Conference on the management of gastroesophageal reflux disease in adults update 2004. Can J Gastroenterol 2005, 19:15-35.

28. Kahrilas PJ, Shaheen NJ, Vaezi MF, et al: American Gastroenterological Association Medical Position Statement on the management of gastroesophageal reflux disease. Gastroenterology 2008, 135:1383-1391, 1391 e1-5.

29. Zacny J, Zamakhshary M, Sketris I, et al: Systematic review: the efficacy of intermittent and on-demand therapy with histamine $\mathrm{H} 2$-receptor antagonists or proton pump inhibitors for gastro-oesophageal reflux disease patients. Aliment Pharmacol Ther 2005, 21:1299-1312.

30. Ahrens D, Chenot JF, Behrens $G$, et al: Appropriateness of treatment recommendations for PPI in hospital discharge letters. Eur J Clin Pharmacol 2010, 66:1265-1271.

31. Ho PM, Maddox TM, Wang L, et al: Risk of adverse outcomes associated with concomitant use of clopidogrel and proton pump inhibitors following acute coronary syndrome. JAMA 2009, 301:937-944.

32. Bhatt DL, Cryer BL, Contant CF, et al: Clopidogrel with or without omeprazole in coronary artery disease. N Engl J Med 2010, 363:1909-1917.

33. Southworth MR, Temple R: Interaction of clopidogrel and omeprazole. N Engl J Med 1977, 2010:363.

34. Dial S, Delaney JA, Barkun AN, Suissa S: Use of gastric acid-suppressive agents and the risk of community-acquired Clostridium difficileassociated disease. JAMA 2005, 294:2989-2995.

35. Laheij RJ, Sturkenboom MC, Hassing RJ, et al: Risk of community-acquired pneumonia and use of gastric acid-suppressive drugs. JAMA 2004, 292:1955-1960.

36. Yang $Y X$, Lewis JD, Epstein $S$, Metz DC: Long-term proton pump inhibitor therapy and risk of hip fracture. JAMA 2006, 296:2947-2953.

37. Corley DA, Kubo A, Zhao W, Quesenberry C: Proton pump inhibitors and histamine-2 receptor antagonists are associated with hip fractures among at-risk patients. Gastroenterology 2010, 139:93-101.

\section{Pre-publication history}

The pre-publication history for this paper can be accessed here: http://www.biomedcentral.com/1471-230X/12/18/prepub

doi:10.1186/1471-230X-12-18

Cite this article as: Pouchain et al:: Gaviscon ${ }^{\circledR}$ vs. omeprazole in symptomatic treatment of moderate gastroesophageal reflux. a direct comparative randomised trial. BMC Gastroenterology 2012 12:18.

\section{Submit your next manuscript to BioMed Central and take full advantage of:}

- Convenient online submission

- Thorough peer review

- No space constraints or color figure charges

- Immediate publication on acceptance

- Inclusion in PubMed, CAS, Scopus and Google Scholar

- Research which is freely available for redistribution

Submit your manuscript at www.biomedcentral.com/submit
C Biomed Central 